\title{
Complementary Value of Databases for Discovery of Scholarly Literature: A User Survey of Online Searching for Publications in Art History
}

\section{Erik Nemeth}

\begin{abstract}
Discovery of academic literature through Web search engines challenges the traditional role of specialized research databases. Creation of literature outside academic presses and peer-reviewed publications expands the content for scholarly research within a particular field. The resulting body of literature raises the question of whether scholars prefer the perceived broader access of Web search engines or opt for the precision of field-specific research databases. Surveys of art historians indicate a complementary use of online search tools with a reliance on field-specific research databases to discover authoritative content. Active use of Web search engines and initiatives for open access suggest that research databases will integrate into an evolving Web-based infrastructure that supports discovery and access of scholarly literature.
\end{abstract}

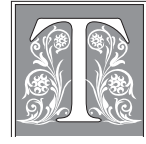

he coming of age of "digital natives" and the perceived omnipotence of Web search engines pose two related questions for producers of online search tools for scholarly research: "What is the future value of field-specific research databases?" and "What is the future value of specialized metadata?" The general success of Web search engines, on the one hand, challenges producers of fieldspecific databases but, on the other hand, may eventually depend on the production of specialized metadata to prove effective in searching for scholarly literature. The middle ground of humanities databases that enable full-text searching of and access to scholarly literature provide an alternative. The perceptions of academics who search for scholarly literature can provide insights into the relative value of each of the three paradigms.

In 2008, the Department of Research Databases at the Getty Research Institute conducted a user survey. The survey strove to identify the most frequently accessed resources for searching of scholarly literature in art history and to ascertain the most valued features of search tools and content of databases. The range of types of search tools included aggregate library catalogs, art-history citation databases with abstracts and indexing, humanities databases with full-text content, and Web search engines. Features included metadata, content

Erik Nemeth is Research Analyst at www.culturalsecurity.org in Santa Monica, California; e-mail: erik.nemeth@culturalsecurity.org. (C) Erik Nemeth 
listings, and search-result ranking, and content ranged from peer-reviewed publications to Web blogs. By delineating the responses according to age, the survey also compared the needs of "digital natives" to traditional academics; and, by delineating the responses according to role, the survey dissected various applications of the search tools in question. Collecting information on the confidence that different roles and age groups place in different types of search tools provided a detailed assessment of the preferences and needs of academics who search for scholarly literature in art history.

\section{Background}

Online field-specific research databases follow from a long history of abstracting and indexing services. ${ }^{1}$ Publications that provide abstracts of printed books appeared as early as the 1600s, and abstracting and indexing services specializing in a specific field established a presence in the 1800s. Services that cover the sciences migrated to a digital platform in the mid 1900s, and services specializing in the arts and humanities made databases available online by the 1980s. Services providing online full-text of journals across fields began in the mid 1990s, ${ }^{2}$ and large-scale projects for digitizing books followed advances in Web search engines over the past decade. $^{3}$

The accelerating innovation in methods of searching for scholarly literature suggests potential differences in use between the emerging generation of "digital natives" and the "digital immigrants." ${ }^{* 4}$ Over the past few years, however, studies have suggested that the differences may not be as radical as predicted. ${ }^{5}$ Educators adapt by engaging students of the digital age with Web technologies. ${ }^{6}$ The aggregation of online searching of library holdings ${ }^{7}$ and journal articles ${ }^{8}$ has the potential for a unifying, as opposed to a dividing, effect on digital natives and immigrants. Aggregation also distances the user from information sources, ${ }^{9}$ and the effectiveness differs depending on the field being searched. ${ }^{10}$

Despite aggregation, abstracting and indexing services in the sciences remain competitive with full-text search tools for particular fields. By example, specialized indexing of chemical compounds provides an advantage over full-text keyword searches of literature in chemistry. ${ }^{11}$ In the humanities, reports suggest the limited effectiveness of the academic versions of generalized Web search engines in covering articles for fields such as art history. ${ }^{12}$ Academics in the arts and humanities have reaffirmed the value of the metadata provided by field-specific research databases. ${ }^{13}$ As the traditional research methodologies in the field of art history take advantage of digital representations of visual objects, the effectiveness of online searching for images may depend on specialized indexing. ${ }^{14}$ The potential role of metadata in searching the $\mathrm{Web}^{15}$ suggests that strengths of one type of search tool may complement another. The acknowledged individual strengths of Web search engines, full-text databases, and field-specific research databases leads to the question of the relative perceived value of the various types of online tools for searching scholarly literature.

\section{Research Methods and Data}

\section{Survey Instrument and Promotion}

The survey comprised sixteen questions that queried responses on: 1) frequency of use and confidence in particular databases; 2) desired content type (journal articles, monographs, reviews ...); 3) usage of database features (search forms, metadata, results ranking ...); and 4) field of study, role, and general information about users. Fourteen of the questions had a multiple-choice format, and two of the

\footnotetext{
*In this paper, "digital immigrant" refers to an individual who has adopted use of a computer and the Internet in professional practices; "digital native" refers to an individual who has had the benefit of access to a computer and the Internet since primary education.
} 


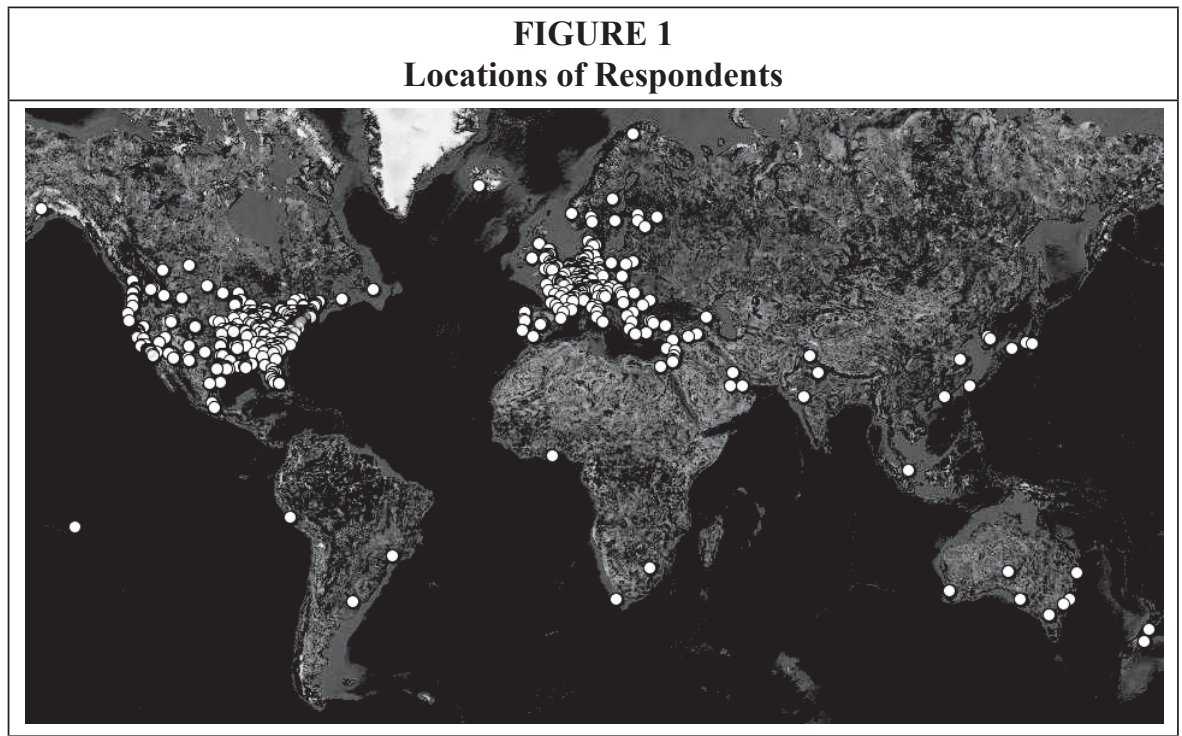

questions allowed for free-text answers.

Promotion of the survey targeted an audience concerned with the study of the history of Western art. A link to the survey appeared on listservs for art history in the United States, and associations of art librarians, art history, and other humanities in the United States, Canada, and Europe received a link to the survey for distribution to members and colleagues. The survey remained accessible for approximately two months (March-April 2008).

\section{Sample Size}

A total of 2,077 users of online research tools for art history responded to the survey, and 1,976 respondents answered most of the questions on the survey. The absolute number of academics in art history, let alone all potential users of information on art history, is difficult to estimate. Consequently, the percentage of the "population" that the sample represents is difficult to calculate. The demographics of the respondents, however, demonstrate a comprehensive range of roles, areas of specialization, and geographic locations.

\section{Demographics}

Distribution of the survey targeted students, librarians, professors, and other scholars of art history and museum professionals. The sample primarily represents users in North America, Europe, and Australia, which are the main geographic regions in which scholars pursue research

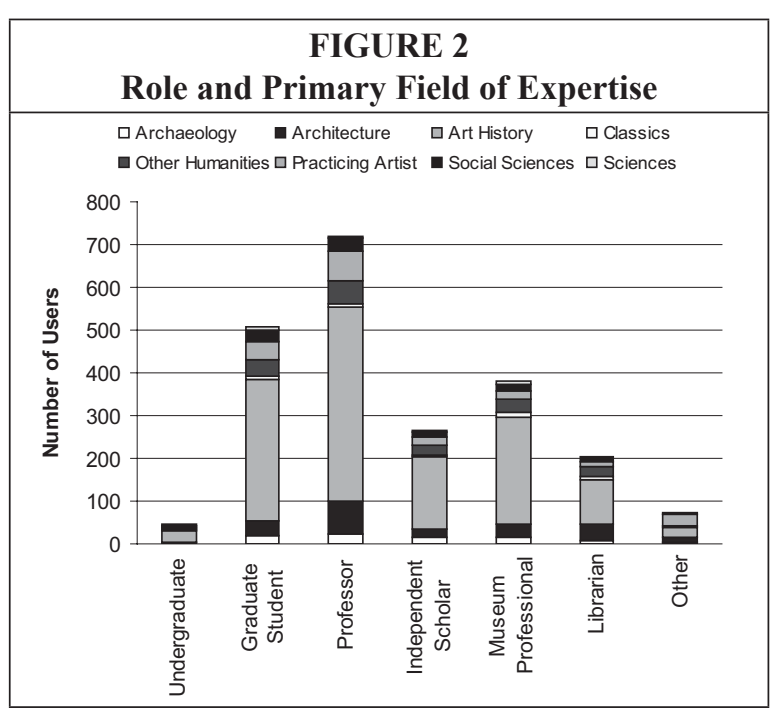




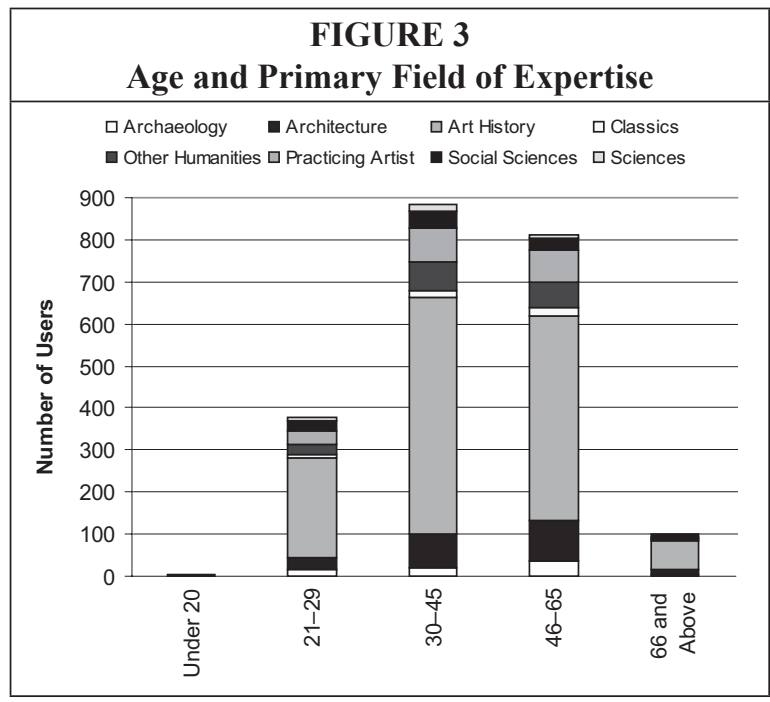

results, the relatively small number of respondents who are undergraduates will be combined with the larger number of graduate students to form the group "students." The relatively small number of other roles will not be included in the analyses. After consolidation, five roles will be represented in the analyses: students, professors, independent scholars, museum professionals, and librarians.

\section{Subject Matter}

To gain an understanding on the history of Western art (figure 1). A few questions collected information on the range of roles and areas of expertise of the respondents. A majority of respondents identified themselves as professors and graduate students followed by museum professionals, independent scholars, librarians, and others, whose roles ranged from artists, attorneys, administrative personnel, and dealers to technology professionals (figure 2). Most of the respondents are over 30 years old with relatively even distribution across the two spans of 30-45 and 46-65 (figure 3). A majority of users in the sample indicated art history as the primary area of expertise, and the distribution across both ranges provides some degree of assurance that the results of the survey were not biased by role or age.

For the purposes of analyzing the of the use of online research tools in art history, the survey contained questions about the following resources that may be accessed through the Web: Arts $\mathcal{E}$ Humanities Citation Index, Art Index, Artbibliographies Modern, ArtLibraries.net, Avery Index to Architectural Periodicals, Bibliography of the History of Art $(B H A)^{16}$, FRANCIS, Web search engines (such as Google, Google Scholar, Yahoo, Microsoft Academic Search), Humanities Full Text, JSTOR, and Kubikat. The resources could be roughly divided into three groups according to specificity of their scope of coverage from art history to humanities to general information (figure 4).

\section{Results and Analyses}

The results and analyses will be presented in the order that the questions appeared in

\begin{tabular}{|c|c|c|c|}
\hline \multicolumn{4}{|c|}{$\begin{array}{c}\text { FIGURE } 4 \\
\text { Types of On-line Resources Referenced in Survey Questions }\end{array}$} \\
\hline Specificity & Art History & Humanities & General \\
\hline $\begin{array}{l}\text { Online } \\
\text { Resource }\end{array}$ & $\begin{array}{l}\text { Art Index } \\
\text { Artbibliographies Modern } \\
\text { ArtLibraries.net } \\
\text { Avery Index } \\
\text { Bibliography of the History } \\
\text { of Art } \\
\text { Kubikat }\end{array}$ & $\begin{array}{l}\text { Arts \& Hum. Citations } \\
\text { Index } \\
\text { FRANCIS } \\
\text { Humanities Full Text } \\
\text { JSTOR }\end{array}$ & $\begin{array}{l}\text { Google } \\
\text { Google Scholar } \\
\text { Yahoo } \\
\text { MS Academic } \\
\text { Search }\end{array}$ \\
\hline
\end{tabular}




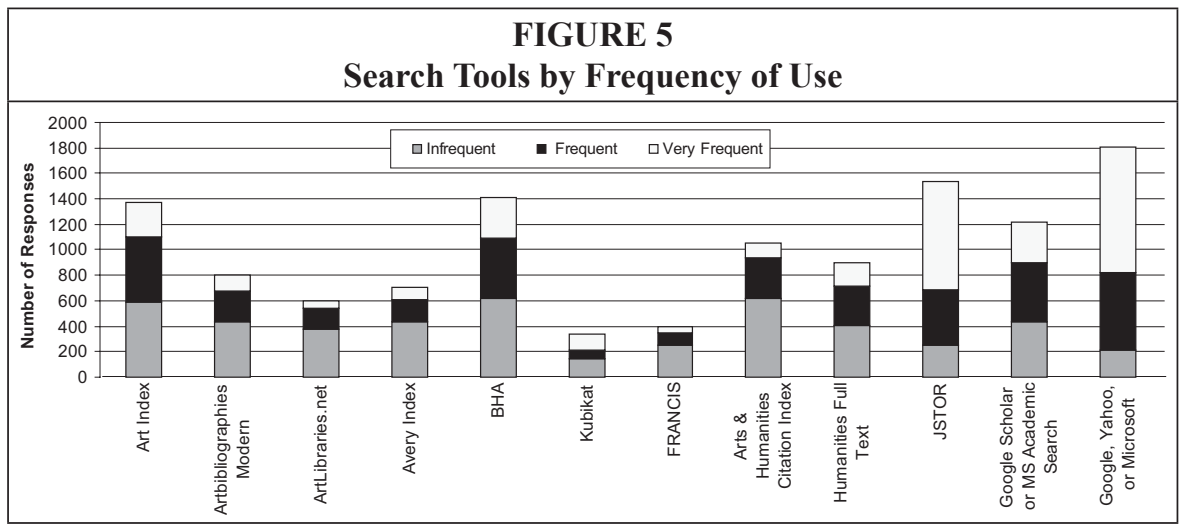

the surveys: frequency of use, confidence in search results, usefulness of features, importance of material, and use of search fields. In addition, the combined use of resources will be analyzed.

\section{Frequency of Use}

The sample showed considerable variation in access of individual resources and the frequency of use of a particular resource (figure 5). Four options for response were provided: "not used," "infrequent," "frequent," and "very frequent." The responses were not qualified in the survey, so distinctions between the choices were left to the discretion of the respondents. Within the resources specific to art history, Art Index and BHA were most accessed and showed the highest frequency of use, while Kubikat showed the least frequent use. The difference between the most frequently used to the least frequently used database was significant, with $B H A$ being accessed by four times as many users as Kubikat. For the resources more general to the humanities, JSTOR had the most users, who appear to access the resource quite frequently. The relatively high use of Web search engines reflects that such resources are used in conjunction with more specialized search tools.

Use of resources was also examined by role and age. The proportionate number of respondents from a particular role or age group was roughly the same across resources. The similarities suggest that the responses for any one tool can provide a representative sampling. To assess trends across roles and age groups, the following analyses will focus on the most used resources within each group of specialization. Art Index and BHA will represent "specialized" databases, JSTOR

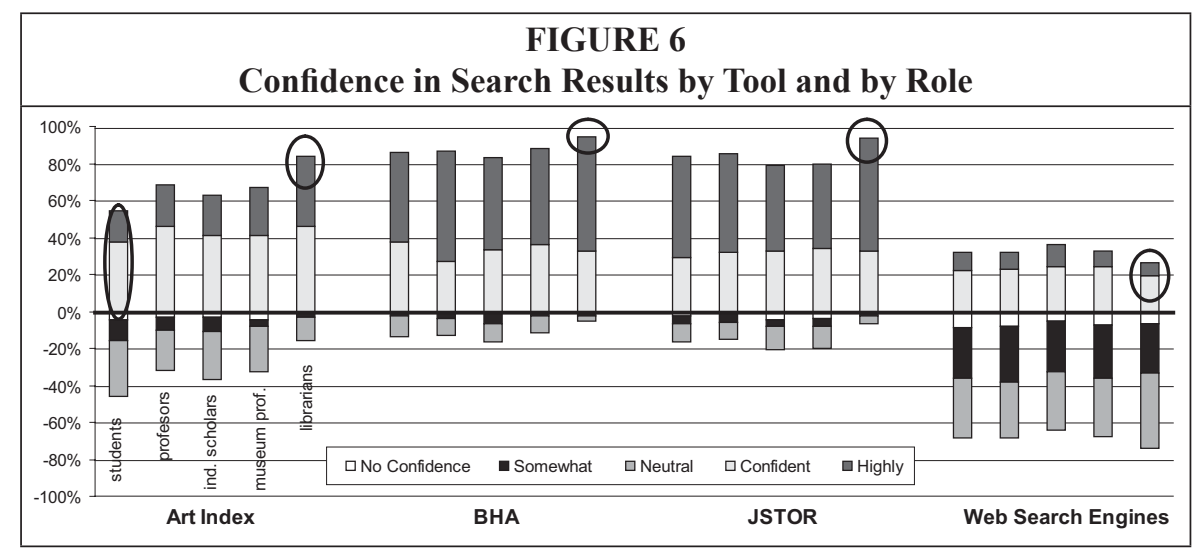




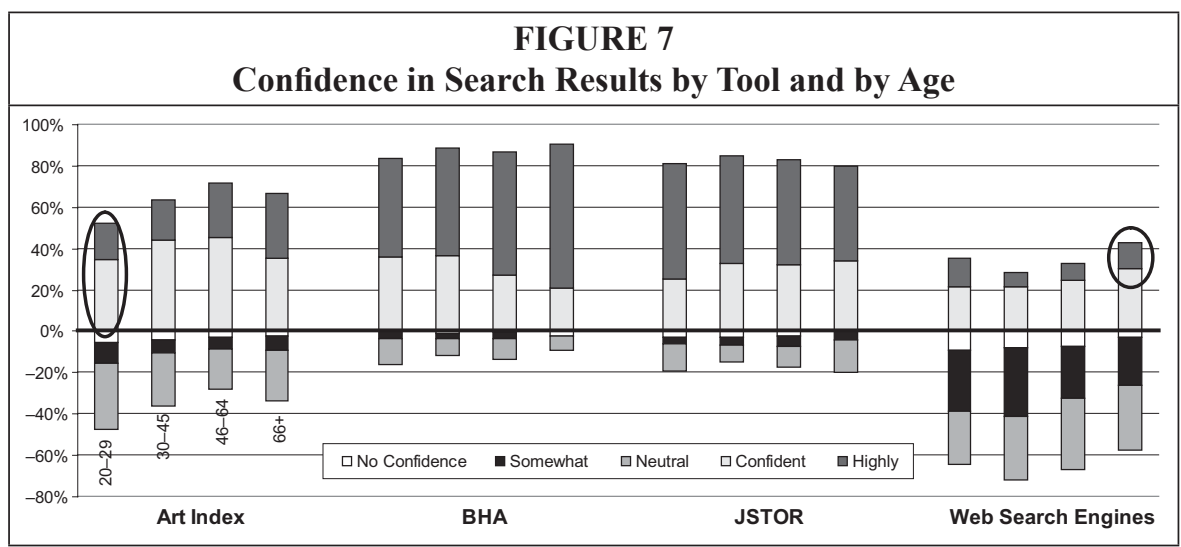

will represent the less specific "humanities" databases, and responses for the Web search engines will be combined as "general" search tools.

\section{Confidence in Search Results}

One purpose of the survey was to collect information on confidence that different groups have in online search tools. Through the question, "When considering the quality of search results-relevance, comprehensiveness, authoritativenesshow confident are you in the following search tools?" respondents were asked to consider the relative value of the various online resources.

Results showed some variation across search tools and across roles (figure 6). Confidence was relatively high for Art Index, BHA, and JSTOR and significantly lower for the Web search engines. Among the search tools that specify coverage of publications, BHA and JSTOR held slightly more confidence than Art Index. Across roles, the confidence for any particular resource was relatively even, with the following two exceptions: Students showed slightly less confidence in Art Index than the other roles, and librarians showed slightly more confidence in each of the search tools that specify coverage and slightly less confidence in the Web search engines.

Results across age groups showed a similar pattern of confidence to the roles across search tools (figure 7). All respondents showed significantly higher confidence in the specialized tools and the highest confidence in $B H A$ and $J S$ $T O R$. Across age groups, the response of the 20-29 group appears to mirror the student group. Within a particular search

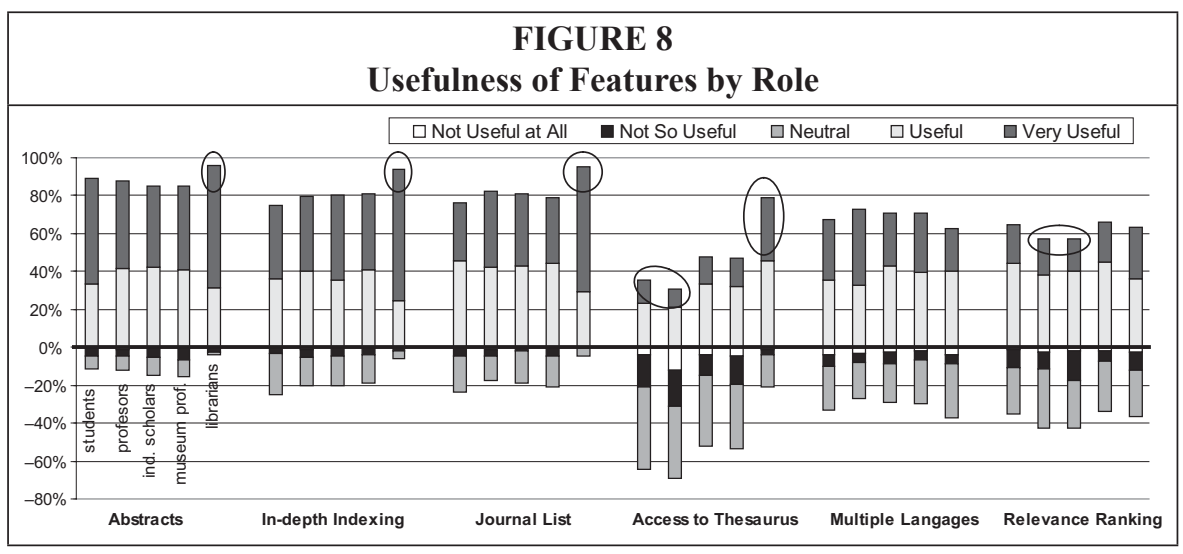


tool, the groups showed subtle variations in confidence. One noteworthy variation is in the Web search engines. The 66+ group showed more confidence than the 20-29 group.

\section{Usefulness of Different Database Features}

Each search tool emphasizes certain features relevant to determining the relevance of documents for a particular task. Highly specialized research databases, such as $B H A$, focus on abstracting and indexing manually selected publications. Other databases, such as JSTOR, focus on more generalized indexing of select material, while Web search engines include all material that is openly accessible on the Web. The question, "Please rate the usefulness of each of the features that are included in or available through online resource" listed six features: "abstracts/ summaries," "in-depth indexing," "list of covered periodicals," "access to thesaurus," "searching in a language other than English," and "relevance ranking of results."

Each feature elicited variations across roles (figure 8). For "abstracts," "in-depth indexing," and "journal list," most of the respondents for all roles found the features useful, with librarians indicating particularly high appreciation. "Access to thesaurus" showed the most variation. Fewer than half of the students and professors who responded found such access useful, while about half of the independent scholars and museum professionals acknowledge the value of the feature. Librarians again had the highest appreciation. Being able to search in a language other than English found moderately high approval with $60 \%-70 \%$ of all respondents across all groups. Relevance ranking of search results also found moderate approval, with professors and independent scholars having a slightly lower appreciation than the other groups.

All age groups showed the highest approval for abstracts as a feature in determining the relevance of documents in a search result (figure 9). Appreciation for "in-depth indexing" and "journal list" was also quite high across all groups, with the 20-29 group showing slightly less appreciation than the other groups. Having access to non-English-language publications seemed moderately important across age groups, and fewer than half of all respondents in each age group found value in accessing the feature of a thesaurus. The value of relevance ranking showed the largest variation across age groups, with a steady decline with from 20-29 to $66+$. The variation may indicate an increasing dependence on relevance ranking for users who were "born digital" and have become accustomed to the ranking provided by Web search engines.

\section{Importance of Different Types of Material}

Different search tools cover different types of material according to the edito-

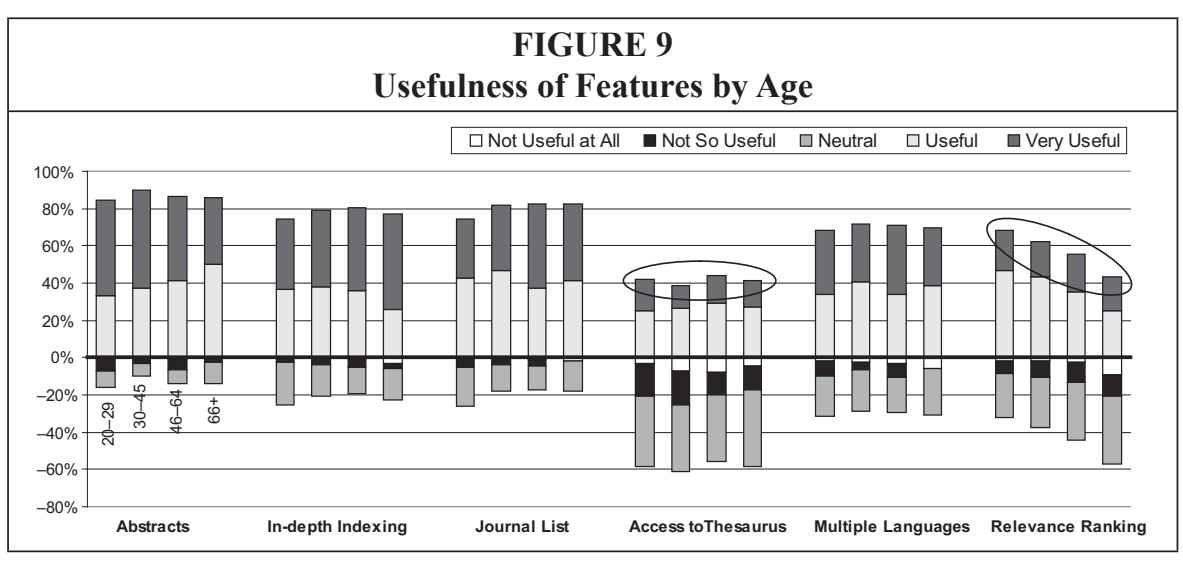


rial strategy. Some search tools focus on a particular type of material, such as JS$T O R$, which specializes in journal articles. Other databases, such as $B H A$, select from a range of materials that represent the scope of the covered field. For such search tools, responses to the question, "How important is it that an online resource covers the following material?" are important to informing the editorial strategy. Respondents could indicate the relative importance of a range of material: "blogs," "books," "book reviews," "conference proceedings," "dissertations," "exhibition catalogues," "exhibition reviews," "journals," "non-peer-reviewed material," "self-published material," and "Web sites."

The importance of material to respondents showed great variation, with considerable agreement across roles (figure 10). Books, journals, dissertations, and conference proceedings were highly valued, as perhaps expected in academia. Exhibition catalogs were also highly valued, as perhaps expected for academics in art history and museum professionals. Book reviews and exhibition reviews held relatively high value. Non-peer-reviewed material and Web sites held similar moderate value, with less than half the respondents finding the material important. Self-published material held relatively low importance to a majority of respondents, and blogs seemed relatively unimportant.

Only subtle variations exist across roles. In the highly valued material, independent scholars and museum professionals had slightly more appreciation for journals than the other roles, and librarians showed more appreciation for conference proceedings than the other roles. At the next level of valued material, professors showed slightly more appreciation for book reviews. For the less valued material, independent scholars and museum professionals had slightly more apprecia-

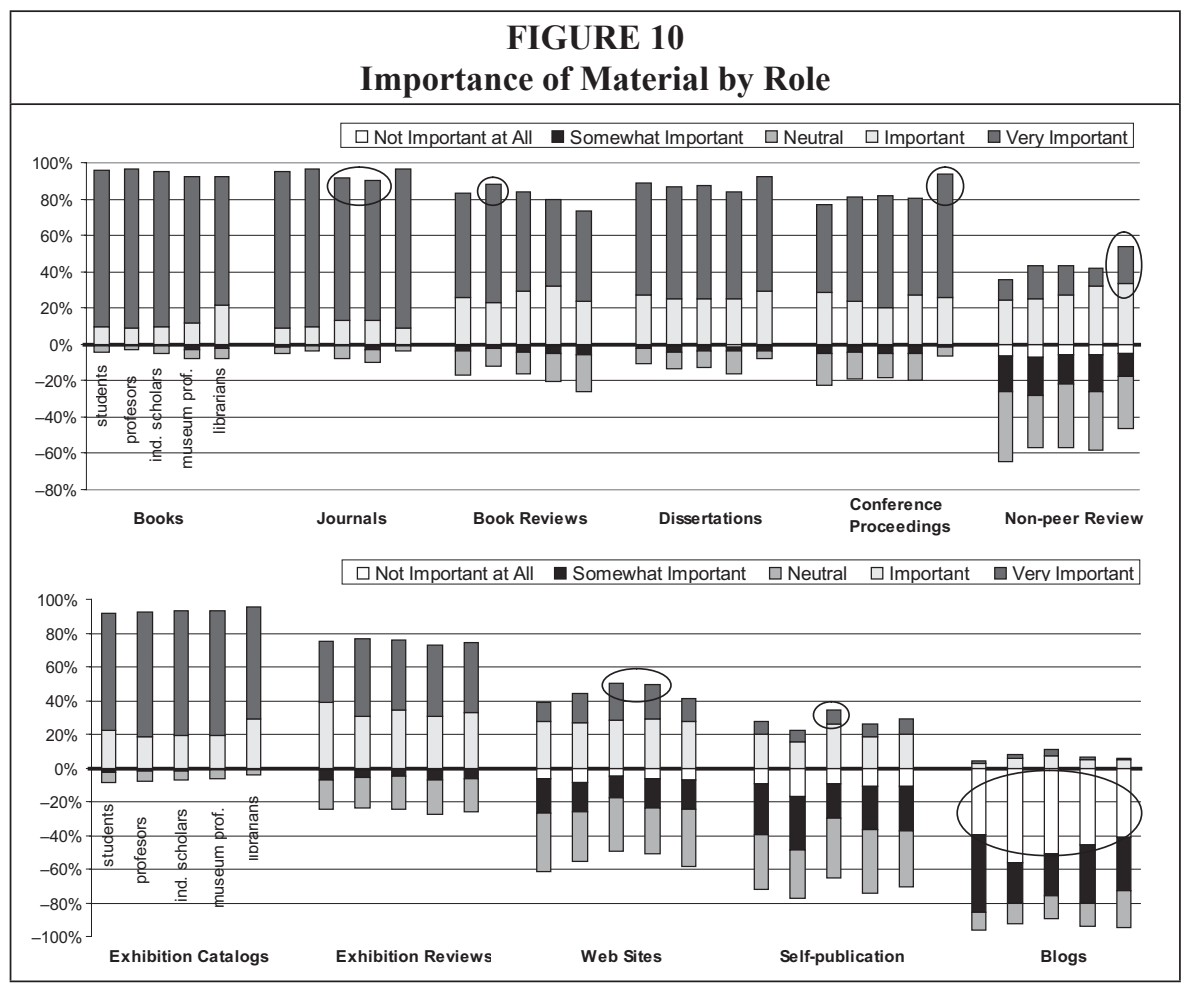




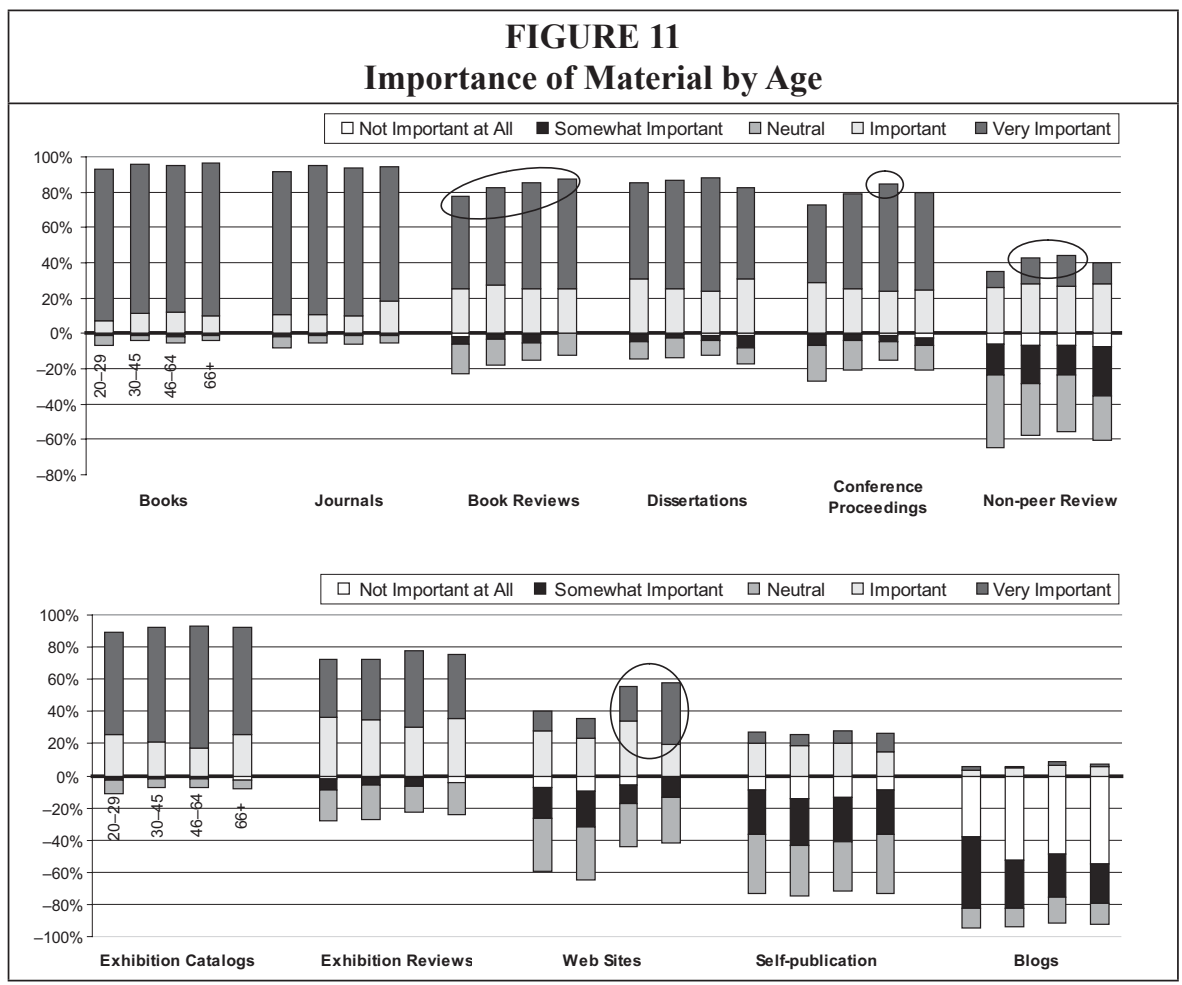

tion for Web sites, and librarians valued non-peer-reviewed material more than the other roles. For the least valued material, independent scholars showed slightly more appreciation for self-published material and blogs than the other roles.

All age groups followed the same pattern of importance of material as for roles, with some more accented differences across age groups for particular types of material (figure 11). Appreciation of the highly valued material showed only slight variation for conference proceedings for which the age group 46-64 formed a peak. For the relatively highly valued material, appreciation for book reviews shows steady increase with increasing age groups. For the less valued material, the two middle-age groups had slightly more appreciation for non-peer-reviewed material, and the two oldest age groups had more appreciation for Web sites, surprisingly, than the younger age groups. In particular, about 40 percent of the $66+$ group found Web sites "very important."

\section{Relative Use of Search Fields}

The user interfaces to search tools that are designed for searching scholarly literature tend to include specific fields. With the Web search engines as possible exceptions, the search tools generally include fields relevant to identifying publications. The question "When conducting research in your area of expertise, how do you typically search?" asked respondents to select one or more types of search fields: "title," "publisher," "period," "keyword," "author," and "subject."

The relative use showed significant variation across fields and across roles (figure 12). "Title," "author," "subject," and "keyword" all showed high use, and, not surprisingly, "period" and "publisher" showed lower use across all roles. For particular search fields, librarians as a group showed significantly higher use for "subject" and for the generally less used fields of "publisher" and "period." Students and professors also stood out with a higher use "author" as a search field. 


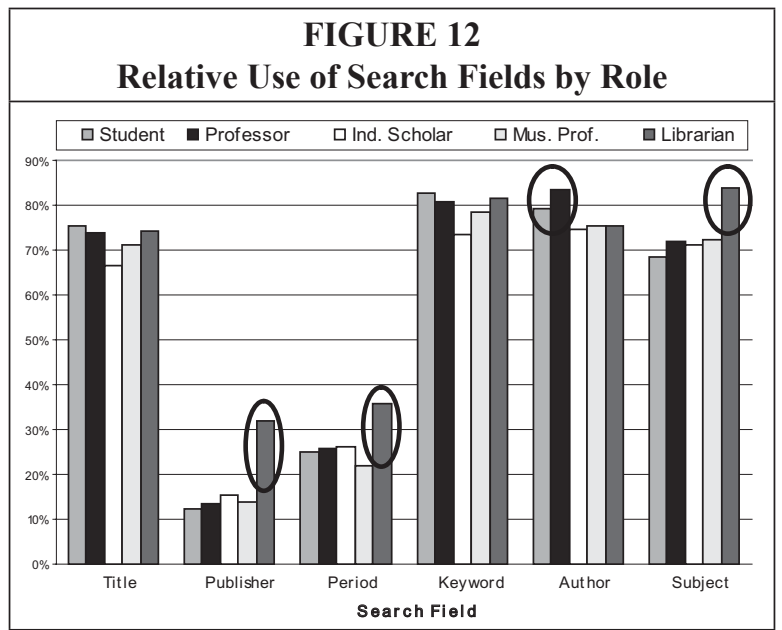

Independent scholars showed different preferences by showing less use of fields "title" and "keyword" than the other roles.

All age groups followed the same pattern of use of search fields as for roles, with some more accented differences across age groups for particular search fields (figure 13). Within the highly used fields, use of "author" and "keyword" showed variation across age groups. Use of "author" increased slightly across groups of increasing age, while use of "keyword" showed an opposite and more pronounced effect, with the 66+ group displaying a marked drop in use. The 66+ group also seemed to have markedly less need for the "publisher" field than the other age groups.

\section{Combined Use of Online \\ Search Tools}

The high use of Art Index, $B H A, J S T O R$, and Web search engines indicates that respondents use a combination of search tools. An inspection of which tools a particular user employs reveals slight variation for different combinations (figure 14). While a fair number of respondents indicated use of all four search tools, a greater number of respondents indicated a combined use of three search tools. Approximately 25 percent more respondents indicated a combined use of Art Index/JSTOR/Web Search over the combined use of all four search tools.

The combination of use also varied slightly for those respondents who indicated art history as an area of primary expertise (figure 14, light grey portion) and those who indicated another field of specialization (figure 14, dark grey portion). The combinations of BHA/JSTOR/Web Search and Art Index/JSTOR/Web Search had the most responses for specialization in art history and others combined. Specialists in art history, however, had slightly higher preference for $B H A / J S T O R /$ Web Search, while other specializations had slightly higher preference for Art Index/JSTOR/Web Search.

\section{Discussion}

The survey enabled a comparison of different types of online search tools, of preference according to role and age, and of combined use of tools. An examination of frequency of use identified

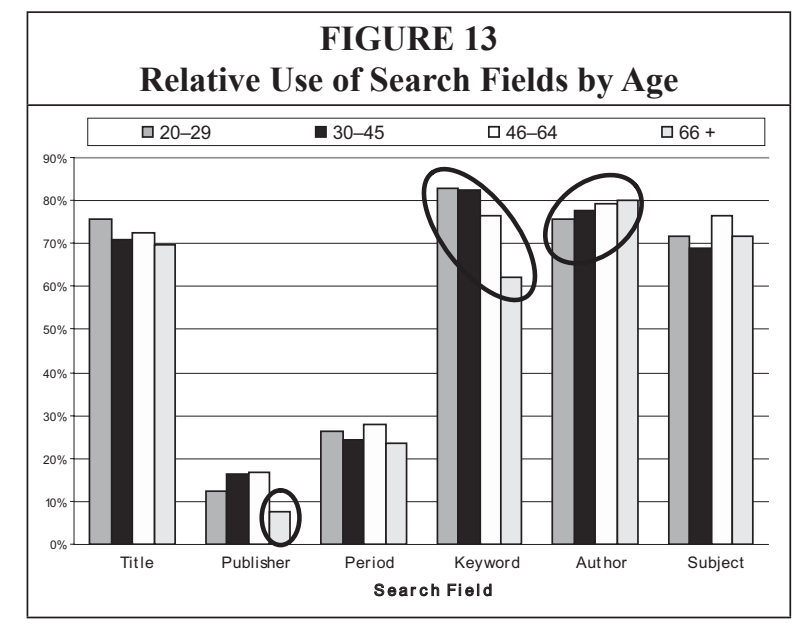




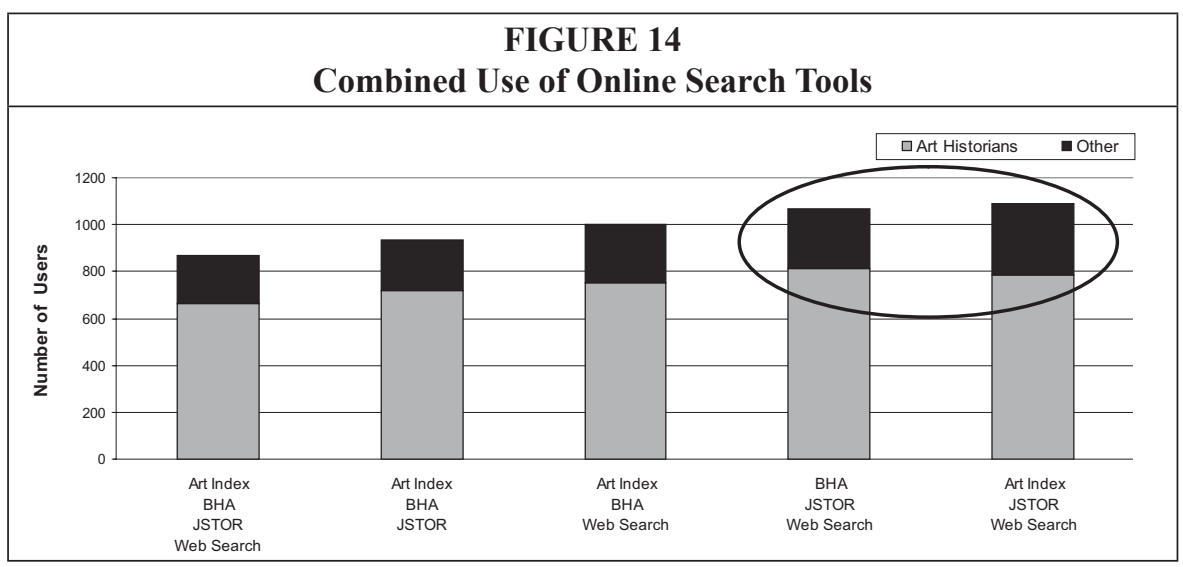

the four most popular databases listed in the survey. Art Index, BHA, JSTOR, and Web search engines also happen to represent three different types of online search tool. With distinct foci, each type of search tool specializes in providing a particular feature of particular value to the user. Specialized research databases, such as Art Index and BHA, emphasize metadata in the form of abstracts and indexing; full-text databases, such as JSTOR, avail the user of comprehensive keyword searching and document access; and Web search engines enable indiscriminate discovery of material on Web pages.

Frequency of use provides a measure of the popularity of a particular search tool but does not provide a complete sense of the perceived value of a tool. In retrospect, a question about ease of access and ease of use of a particular search tool would have been appropriate for qualifying responses about frequency of use. Measuring the confidence that users have in the search results of a tool provides another dimension to the perception of value. Users show relatively high confidence in the search results from the humanities full-text databases and databases with specialized metadata, while the search results from Web search engines held lower confidence. The distinguishing features of field-specific research databases might explain the difference.
The features available in a particular search tool also contribute to the perceived value of the tool. The highly rated usefulness of abstracts and in-depth indexing indicate the value of field-specific metadata, and the closely rated usefulness of a journal list demonstrates an appreciation for understanding the scope of content of a database. The perceived value of a thesaurus across roles showed one of the greater variations in the results of the survey. The significantly higher percentage of librarians that find the thesaurus a "very useful" feature suggests a value that the other roles have yet to exploit. For example, in some cases, thesauri contain translations of indexing terms, so the expressed appreciation for searching in a language other than English indicates that users have yet to exploit thesauri accordingly. In contrast to the common appreciation for the feature of multiplelanguage representation, relevance ranking clearly had more value for younger users. Ranking of search results in the paradigm of Web search engines may set the expectations of "digital natives" who face a seemingly constantly expanding pool of literature in the online environment.

Despite increasing discovery and expanding access online, users of all roles highly valued peer-reviewed journals and literature on exhibitions and conferences, while Web sites, self-publication, and blogs held less value. The trend showed 
little variation across roles, but across ages the perceived importance of book reviews and Web sites seems to decrease for younger users. The gradual increase in importance of book reviews with age might reflect the maturation of research methods or could indicate a decreasing perceived relevance of books. The stark distinction in perceived importance of Web sites had no apparent explanation. In particular, a significant proportion of the respondents over the age of 65 considered material on Web sites "very important." Overall, however, the predominant importance of peer-reviewed publications and literature on exhibitions has implications for the parameters by which users search.

The high use of search fields other than keyword indicates the persistent value of interfaces specialized for literature searches. Unity across roles and age groups on the relatively high use of title, keyword, author, and subject demonstrates a broad need for specific search terms that transcends conditioning of the single text box of generalized Web search engines. The increasing use of keyword by younger age groups and the decreasing use of author by younger age groups suggest a trend for a preference of searching content in contrast to citation information. The relatively low use of publisher and period across age groups indicates a point of diminishing returns of specialized search terms in general, but the significantly higher proportion of librarians that use the publisher and period suggests value in tailoring of interfaces for particular audiences.

The results indicate that individual users take advantage of a variety of search tools. Combinations of search tools included not only two distinctly different types of tools (such as citation indexes, full-text databases, Web search engines) but also similar tools (like Art Index and BHA). The various combinations suggest awareness on the part of users about the strengths and limitations of any one tool and about the potential for one tool to complement another.

\section{Conclusion}

Art historians and other academics who draw on literature in art history take advantage of a broad range of online search tools that cover several different types of publications. Popularity provides one measure of value but does not provide a complete assessment of the perceived value of a tool. Users assign varying degrees of confidence to different tools and publications. The measured confidence confirms presumptions about the authoritativeness of the content. Users have more confidence in search results from field-specific databases than from general Web search engines, and users have more confidence in peer-reviewed publications than self-published material. Such results affirm the persistent value of field-specific research databases that cover vetted publications and supply specialized abstracting and indexing.

The rapid pace of innovation in technology has implications for the use of tools across academic roles and across generations. Scholars who utilize online searching for quantitative analysis of full-text data will expand the use of search tools beyond literature review. Librarians who increasingly take on the role of advisors on the use of technology may weight role-specific preferences for online search tools, and by recognizing the value of a thesaurus, librarians will educate users on exploiting resources that naturally develop in parallel with a particular search tool. Vendors of databases may also benefit from making thesauri available for users to expand ordinary keyword searching. Professors who trained on one type of technology will have students with competencies in more current technologies. Consequently, each generation may express preference for different online search tools. Within art history, however, tried methods of facilitating discovery of literature appear to transcend technological innovation in that role and age account for limited variation in preference for search tools. The highly ranked usefulness of abstracts and in-depth indexing 
indicates the invaluable metadata that field-specific research database produce, and the full value of the concurrently produced thesauri has yet to be exploited.

The results of the survey demonstrate a continuing need for specialized authoritative research databases and fulltext literature databases. The survey also confirms that academics in art history do use more generalized search tools that do not explicitly vet content. By inquiring about a range of online search tools for research in art history, the results of the survey reveal the complementary use of different types of search tools for scholarly research. Researchers in art history and related fields value a combination of search tools with a range of features. Continued recognition of the value of abstracts and indexing poses a challenge to providers of field-specific databases as sources of publication expand. A growing demand for open access to full-text and comprehensive searching through a single interface illustrate the increasing expectations of academics. The challenge of effective integration of field-specific metadata, full-text content, and Websearch technologies provides database producers with an opportunity to collaborate on the improvement of online searching for scholarly literature.

\section{Notes}

1. Bonnie Lawlor, "Abstracting and Information Services: Managing the Flow of Scholarly Communication-Past, Present, and Future," Serials Review 29, no. 3 (2003): 200-09.

2. Michael Spinella, "JSTOR and the Changing Digital Landscape," Interlending \& Document Supply 36, no. 2 (2008): 79-85.

3. L. Vincent, "Google Book Search: Document Understanding on a Massive Scale," Ninth International Conference on Document Analysis and Recognition 2, no. 23-26 Sept (2007): 819-23.

4. Marc Prensky, "Digital Natives, Digital Immigrants," On the Horizon 9, no. 5 (2001): 1-6.

5. Sue Bennett, Karl Maton, and Lisa Kervin, "The 'Digital Natives' Debate: A Critical Review of the Evidence," British Journal of Educational Technology 39, no. 5 (2008): 775-86.

6. Crusher Wong, Lilian Vrijmoed, and Eva Wong, "Learning Environment for Digital Natives: Web 2.0 Meets Globalization," in Hybrid Learning and Education: First International Conference, ICHL 2008 Hong Kong, China, August 13-15, 2008 Proceedings, Joseph Fong et al. (Berlin; New York: Springer, 2008): 168-77; Sirje Virkus, “Use of Web 2.0 Technologies in LIS Education: Experiences at Tallinn University, Estonia," Program: Electronic Library and Information Systems 42, no. 3 (2008): $262-74$

7. Chip Nilges, “The Online Computer Library Center's Open WorldCat Program," Library Trends 54, no. 3 (2006): 430-47.

8. Alireza Noruzi, "Google Scholar: The New Generation of Citation Indexes," Libri 55, no. 4 (2005): 170-80.

9. Rebecca Donlan and Rachel Cooke, "Running with the Devil: Accessing Library-Licensed Full Text Holdings through Google Scholar," Internet Reference Services Quarterly 10, no. 3-4 (2006): $149-57$.

10. Kayvan Kousha and Mike Thelwall, "Google Scholar Citations and Google Web/URL Citations: A Multi-Discipline Exploratory Analysis," Journal of the American Society for Information Science and Technology 58, no. 7 (2007): 1055-65.

11. Michael Levine-Clark and Joseph Kraus, "Finding Chemistry Information Using Google Scholar: A Comparison with Chemical Abstracts Service," Science \& Technology Libraries 27, no. 4 (2007): 3-17.

12. Hannah Rozear, "Where Google Scholar Stands on Art: An Evaluation of Content Coverage in Online Databases," Art Libraries Journal 34, no. 2 (2009): 21-25.

13. Erik Nemeth, "Metadata of Art and Architecture Research Databases: The Value of Abstracts and Index Terms to Academics, Librarians, and Museum Professionals," Journal of Library Metadata 8, no. 4 (2008): 293-313.

14. Joan Beaudoin, "Image and Text: A Review of the Literature Concerning the Information Needs and Research Behaviors of Art Historians," Art Documentation 24, no. 2 (2005): 34-37.

15. Tony Gill, "Metadata and the Web," in Introduction to Metadata, Murtha Baca (Los Angeles: Getty Research Institute, 2008): 20-37.

16. As of July 1, 2009, the Getty Research Institute halted production of Bibliography of the History Art. 